\title{
Effect of Lowering Twist Levels on Quality Parameters of Rotor Spun Cotton Yarn
}

\author{
FAROOQ AHMED*, GHULAM YASIN SHAIKH**, AND ASHFAQUE AHMED PATHAN *** \\ RECEIVED ON 13.11.2015 ACCEPTED ON 11.05.2016 \\ ABSTRACT
}

\begin{abstract}
Investigations were made to explore the influence of lowering twist level on quality characteristics of rotor spun yarn. Three levels of yarn linear density (i.e. 40, 35 and 30 tex) and five levels of twist (i.e. 700, $600,550,500$, and 450) were employed during yarn spinning trials. Each twist multiple was investigated at all linear densities for tensile strength, elongation, total $\mathrm{CVm}$ (Coefficient of Mass Variation) imperfection index and hairiness. $100 \%$ cotton yarn samples were prepared on Reiter R-40 at rotor speed of 90,000 rpm. Determination of elongation, yarn strength, hairiness, mass variation, and total imperfections index was carried out on Uster Tensorapid-4 and Uster Tester-4 as per set standards of ISO standard test methods. Based on investigations it is established that yarn strength and elongation declined minutely (Insignificant) with lowering twist levels but still can be confidently used for knitting yarns. However, significant improvement in total imperfection index and marginal enhancement in $\mathrm{CVm}$ were experienced.
\end{abstract}

Key Words: Low Twist Multiples, 100\% Cotton, Rotor Spun Yarn, Strength, Elongation, CVm, Total Imperfection Index.

\section{INTRODUCTION}

I n order to maintain the spinning process; coherence mechanism in rotor spinning is achieved by twist insertion, which as a rule must be higher than the yarn twist required for yarn tenacity. Consequently higher twist levels are used for rotor yarns in comparison to ring spinning to attain the strength equivalent to ring yarn [1-3].

Mechanical properties of yarns are a function of their physical structure and morphology [4]. Owing to structural distinction open end yarn is comparatively weaker than ring yarn at equivalent twist levels [2,5]. Presence of fiber belly bands (bridging or belt fibers) in structure of rotor yarn is a disturbing feature, as they do not contribute significantly in coherence of rotor yarns as compare to conventional ring yarn structure [1,6-8].

Yarns are composed of fibers of different lengths and shapes, resulting in yarns spirals with varying radius, which can form kinks at intervals, and even project from

\footnotetext{
* Department of Textile Engineering, Mehran University of Engineering \& Technology, Jamshoro.

** Department of Industrial Engineering \& Management, Mehran University of Engineering \& Technology, Jamshoro.

*** Department of Civil Engineering, Mehran University of Engineering \& Technology, Jamshoro
} 
the yarn surface. Therefore, it is not the overall length of the fiber that contributes to the yarn strength, but only the spun-in part of it as a result optimum yarn tenacity obtained at higher twist multiple than normal $[4,9]$.

Among other factors, residual torque or twist liveliness of a twisted yarn is the most prominent and fundamental factor contributing to the spirality of single jersey fabrics. If a twist-lively yarn is used for knitting, the resultant loop will no longer be symmetric because of the varying induced torsional strain in the yarn [10]. Moreover, high twist multiple makes the rotor yarn harsher to hand feel. In order to btain a fabric without spirality, balanced twist factors for both ply yarns and single yarns are essential [11].

A high twist multiple is responsible for producing many unfavorable aspects of the yarn such as poor handling to the fabric, reduced production, complications to snarling, poor cover factor, etc. [12-14]. These problems can be addressed by reducing the twist multiple up to certain limits. Lowering of twist levels will improve hand feel, count variation, evenness (mass variation), as well as imperfections [15-17]. Though, strength of yarn will decrease further by reducing twist level. However, the low strength yarn can be confidently used for knitting as yarn strength is not a critical factor in knitting as compared to weaving. This lowering of twist multiple will not only help to trim down the unit price of finished product and relief the manufacturer to compete in international market, but also facilitates the knitter by enhancing the smooth running of yarn on knitting machines, as kinkiness of yarn minimizes with low twists [13,18-19].

Keeping in view the benefits of low twist multiples this study was undertaken to explore the effects of lowering twist level on quality parameters of rotor spun knitting yarn.

\section{MATERIALS AND METHOD}

\subsection{Samples Preparation}

To prepare yarn samples, $100 \%$ Pakistani cotton (MNH93), was tested at HVI (High Volume Instrument) and then processed through Rieter blow room line and card (C-51). 4 ktex carded slivers were then processed through drawing machine (RSB D-35). In order to regulate leveled and homogeneous drawn slivers of 4 ktex, carded slivers were given two passages through drawing machine. Actual mass variation and linear densities of carded and drawn slivers are mentioned in Table 1. These drawn slivers were used to spun yarns of selected linear densities i.e. 30, 35, and 40 tex on a rotor spinning machine Rieter (R-40), atrotor speed of 90,000 rpm. Yarn samples of all linear densities were prepared at twist levels of 700, 600, 550, 500 and $450 \mathrm{tpm}$. Process parameters employed for samples preparation are mentioned in Table 2.

TABLE 1. PROCESS FINDING OF INTERMEDIATE OUTPUTS

\begin{tabular}{|c|c|c|}
\hline \multirow{2}{*}{ Process Product } & Characteristics & Result \\
\hline \multirow{4}{*}{ Carded Sliver } & Characteristics & $2.66 \%$ \\
\cline { 2 - 3 } & Mass variation (U) & $4.05 \mathrm{ktex}$ \\
\cline { 2 - 3 } & Weight of sliver & $0.886 \%$ \\
\hline \multirow{3}{*}{ Drawn Sliver } & Coefficient of variation & $2.62 \%$ \\
\cline { 2 - 3 } & Mass variation (U) & $4.0 \mathrm{ktex}$ \\
\cline { 2 - 3 } & Weight of sliver & \\
\cline { 2 - 3 } & &
\end{tabular}

Mehran University Research Journal of Engineering \& Technology, Volume 35, No. 3, July, 2016 [p-ISSN: 0254-7821, e-ISSN: 2413-7219] 


\subsection{Sample Testing}

Uster Tensorapid-4 was employed to determine yarn strength and elongation at break as per ISO standard test method 2062:1993 [16]. Ten cones from each yarn sample were selected randomly and conditioned for 48 hours at $20 \pm 2{ }^{\circ} \mathrm{C}$ and $65 \pm 5 \%$ relative humidity. Conditioned samples were put to test at an extension speed of $5000 \mathrm{~mm} / \mathrm{min}$ with adjusted gauge length of $500 \mathrm{~mm}$ between the clamps. Twenty readings per cone were taken from each of the ten packages thus an average tensile strength was determined from 200 readings. Similarly after 24 hours conditioning, $\mathrm{CVm} \%$, hairiness and total imperfections (thick places, thin places and neps) were measured with Uster Tester-4 at speed of $400 \mathrm{~m} / \mathrm{min}$ for one min through the respective passage and capacitor plates according to ISO standard test method16549:2004 [15].

\section{RESULTS AND DISCUSSION}

To explore the effects of lowering twist levels on quality characteristics of rotor yarn, cotton material was spun with three linear densities i.e. 40, 35, and 30 tex at rotor speed of 90,000 rpm. Twist levels selected for these linear densities were 700, 600, 550, 500, and 450. Results obtained are reported in Figs. 1-5.

\subsection{Effect of Lowering Twist Levels on Strength and Elongation}

Influence of lowering twist levels on tensile strength and elongation are presented in Figs. 1-2. It is evident from Fig. 1 that tensile strength for all linear densities decrease with lowering twist level from 700-450 tpm. Similar trend is observed with respect to elongation. However, coarser counts have higher yarn strength and elongation than finer counts. Reason behind this effect can be discussed as; the function of twist is to hold the constituent fibers in yarn assembly thus providing coherence to yarn [5]. With decreasing twist levels binding effect of yarn or source of coherence reduces. Furthermore with decreasing twist levels delivery of yarn increases which also affects feeding rate. This increase in feeding and delivery rate reduces the interval of fibers' stay in rotor groove [6], which results in reduction of number of core fibers than number of fibers in intermediate zone. In addition with reducing twist, helix angle of core fibers also decreases due to which lateral force holding the fibers together gets weakened and fibers in yarn are held less tightly. This increases slippage of fibers under tensile loading and the number of fibers contributing to overall strength of the yarn gets reduced. Consequently yarn could not withstand against higher load as well as could not be elongated as much as at higher twist. It is also evident by Fig. 1 that this effect is more pronounced with finer yarn counts.

TABLE 2. SETTINGS OF PROCESS PARAMETERS FOR 100\% COTTON YARN SAMPLES

\begin{tabular}{|c|c|c|c|c|c|}
\hline Twist levels (tpm) & 700 & 600 & 550 & 500 & 450 \\
\hline Hank Sliver (ktex) & 4 & 4 & 4 & 4 & 4 \\
\hline Rotor Diameter (mm) & 31 & 31 & 31 & 31 & 31 \\
\hline Rotor Type & GB & GB & GB & GB \\
\hline Navel & K4K R & w-3 R & w-3 R & W-3 R & K4K R \\
\hline Torque Stop & w-3 & 90,000 & 90,000 & 90,000 & 90,000 \\
\hline Rotor speed (rpm) & 90,000 & 150 & 163.63 & 180 & 200 \\
\hline Delivery Speed (m/min) & 128.57 & & \\
\hline
\end{tabular}

Mehran University Research Journal of Engineering \& Technology, Volume 35, No. 3, July, 2016 [p-ISSN: 0254-7821, e-ISSN: 2413-7219] 
It is apparent from Fig. 2 that elongation also falls with decreasing twist levels for all linear densities. Actually, at high twist levels yarn becomes compact and angle between the fiber spiral position and yarn axis is increased. It boosts up the springy behavior of fibers and is a source of higher elongation. Provided higher compactness also reduces fiber slippage during tensile testing. Furthermore, with lowering twist levels, delivery rate and feeding rate increase which gives less time to adjust the fibers in yarn assembly due to which incidence of wrapper fibers gets amplified. These wrapper fibers act like constriction on the yarn whilst the flow of the strain is along the length of the fibers composing the yarn. As a result elongation drops fairly.

\subsection{Influence of Lowering Twist Level on Coefficient of Mass Variation, Imperfections and Hairiness}

Results obtained regarding CVm, Imperfections index and Hairiness are presented in Figs. 3-5. According to results shown in Fig. 3 coefficient of mass variation decreases with lowering twist levels from700-450 tpm. This means that yarn irregularity for cotton is slightly decreased with lowering twist multiples [20]. CVmrefers to variation in number of fibers in yarn cross-section, variation in the

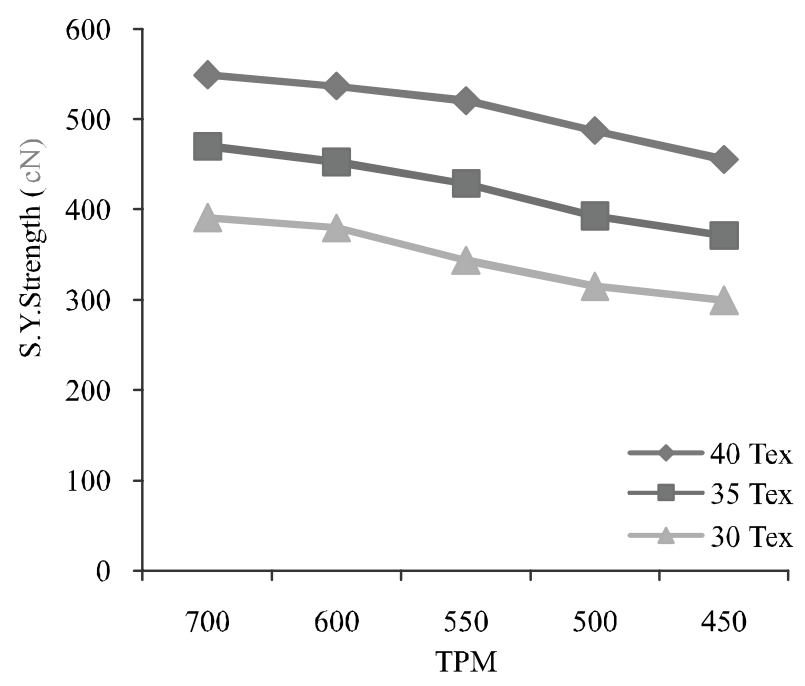

FIG. 1. INFLUENCE OF TWIST ON SINGLE YARN STRENGTH fineness of the fibers themselves as well as variation in fiber inclination to the yarn axis. With decreasing twist multiples yarn compactness and fiber inclination to the yarn axis decreases. Thus, a little improvement in yarn irregularity occurs. Moreover reducing twist level develops bulkiness by reliving strain on fibers. This will reduce frequency of wrapper fibers thus improves evenness. It is found by observing Fig. 4 that total imperfections index reduced by lowering twist levels. At high twist levels neps, thick and thin places become prominent and marked by evenness tester as imperfection[17]. However, by reducing twist multiple compactness of yarn reduces and bulkiness or diameter

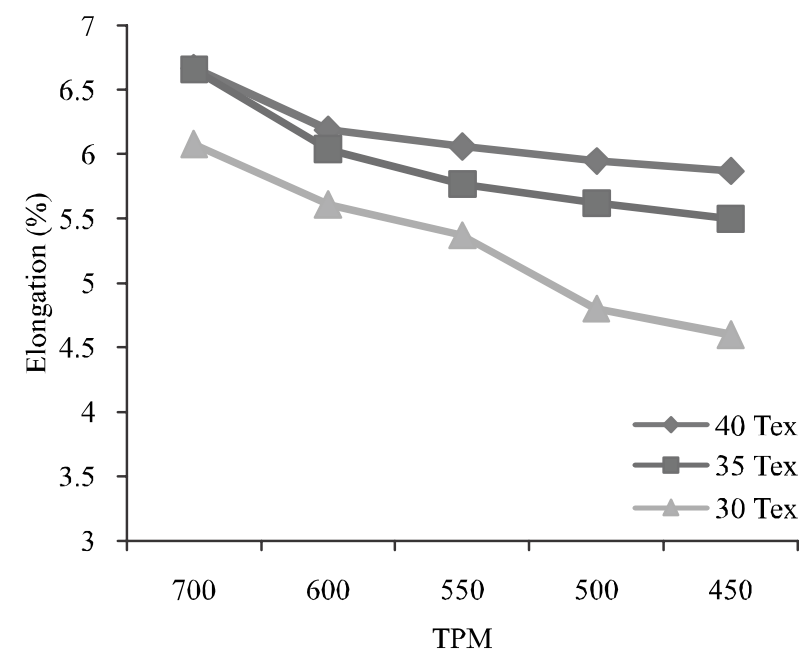

FIG. 2. INFLUENCE OF TWIST ON YARN ELONGATION

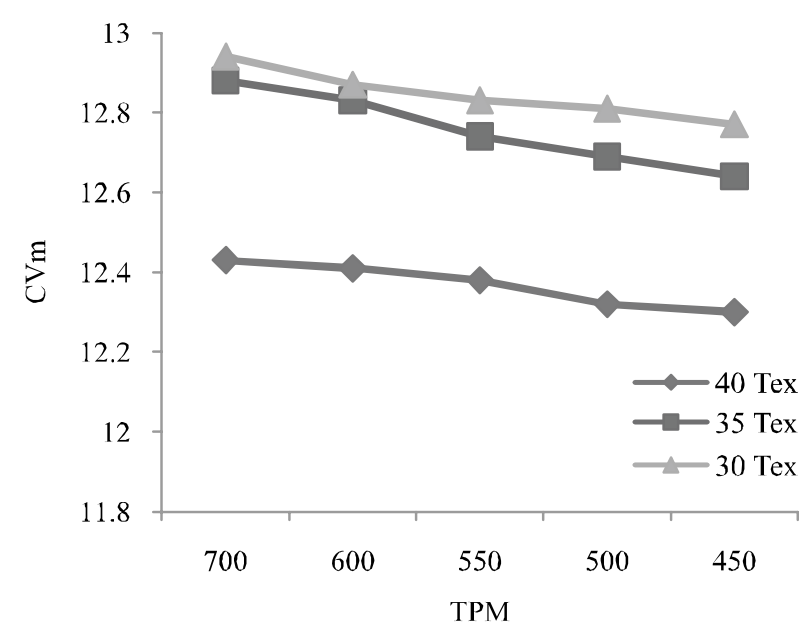

FIG. 3. INFLUENCE OF TWIST ON CVM 
increases which covers up several imperfections, as their sizes becomes diminutive with respect to yarn diameter.

It isevident from Fig. 5 that hairiness of yarn at all linear densities increases with lowering twist multiples. As a matter of fact hairiness decreaseswith increasing compactness of yarn but lowering twist levels makes yarn soft which results in additional protruding ends from yarn surface [6]. Further, this slight increase in hairiness can also be attributed to wobbly wrapper fibers at low twist [17]. The high rotor speed of 90,000 rpm would alsoplay a negative role of increase in hairiness.

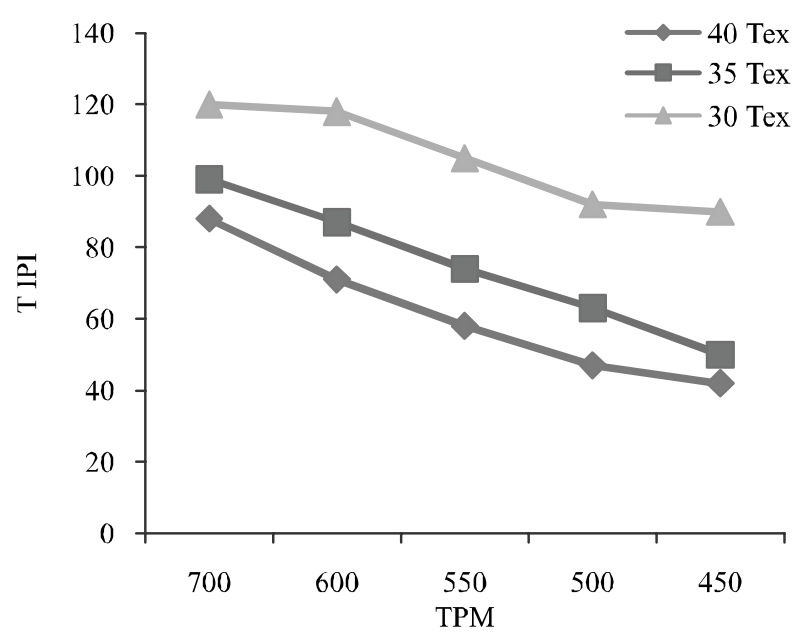

FIG. 4. INFLUENCE OF TWIST ON TOTAL IMPERFECTION

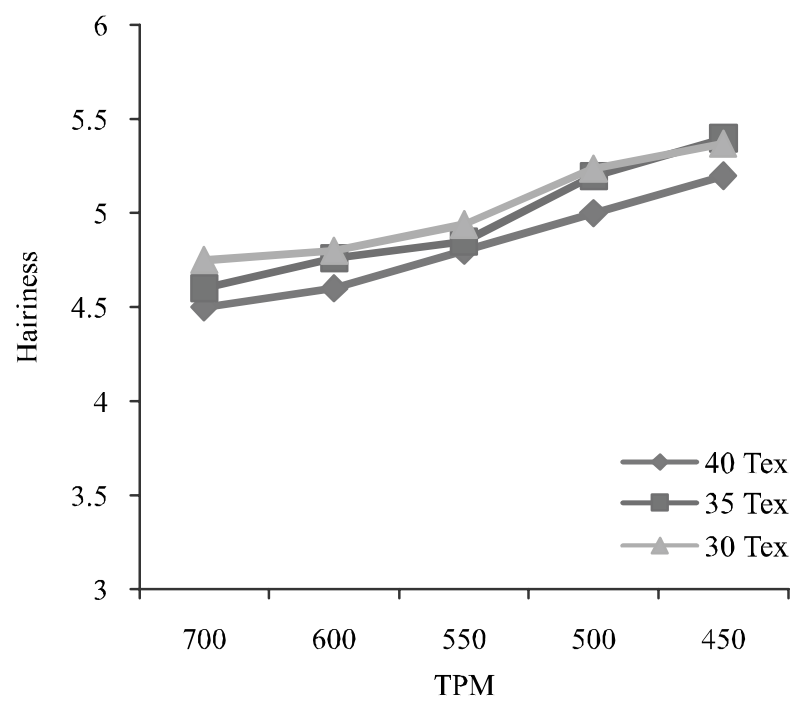

FIG. 5. INFLUENCE OF TWIST ON HAIRINESS

\section{CONCLUSION}

Investigations made to explore the effect of lowering twist levels on quality parameters of rotor yarn reveals that at all linear densities, with lowering twist level, tensile strength and elongation declined to some extent. However, this low strength yarn can be confidently used for knitting as yarn strength is not a critical factor in knitting. On the other hand, fabrication of soft yarn improved evenness and total imperfection index of yarn which will improve hand feel effect and esthetic properties of yarn. An insignificant negative influence on hairiness of yarn was observed at low twist levels.

\section{ACKNOWLEDGEMENT}

We are thankful to Higher Education Commission, Pakistan and Mehran University of Engineering and Technology, Pakistan for providing financial and technical support.

\section{REFERENCES}

[1] Adanur, S., "Wellington Sears Handbook of Industrial Textiles", CRC Press Publication pp. 78-79, England, 1995.

[2] Arain, F.A., Tanwari, A., Hussain, T., and Malik, Z.A. "Multiple Response Optimization of Rotor Yarn Strength, Uniformity, Hairiness and Imperfections", Fiber and Polymer, Volume 13 No. 1, pp. 118-122, 2012 .

[3] Rieter, "Operating Instruction Manual of Rotor R-40", Rieter Machinery Works Ltd. Switzerland, 2002.

[4] Trajkovic, N.D., Stamenkovic, M., Stepavnavic, J., and Radivojevic, D., "Spinning-in Fibres a Quality Factor in Rotor Yarns", Fibres and Textile in Eastern Europe, Volume 15, No. 3, pp. 49-62, 2007 Modeling for the Effect of Rotor Speed, Yarn Twist and Linear Density on Production and Quality Characteristics of Rotor Spun Yarn”, Mehran University Research Journal of Engineering \&Technology, Volume 31, No. 1, pp. 119-128, Jamshoro, Pakistan, January, 2012. 
[6] Gnanasekar, K., Chellamani, P., and Karthikeyan, S., "Influence of Rotor Speed in Open-End Spinning on Yarn Quality", International Journal of Fiber and Textile Research, Volume 15, pp. 164-168, 1990. Navels on Properties of Cotton/Nylon66 Blend (1:1) Rotor Spun Yarn and Wrapper Formation: A Comparison Between Rotor and Ring Spun Yarn”, Journal of Textile Institute, pp. 1-6, 2013.

[8] Salhotra, R.K., and Balasubramanian, P., "11-An Approach to the Optimization of Rotor-Spinning Machine Parameters", Journal of Textile Institute, pp. 128-138, 1986.

[9] Lawrence, C.A., "Fundamentals of Spun Yarn Technology”, CRC Press, pp. 266,316, Leeds, England, 2003.

[10] Tao, X. M., Lo, W.K., and Lau, Y.M., “Torque -Balanced Singles Knitting Yarns by Unconventional Systems Part1: Cotton Rotor Spun Yarn”, Textile Research Journal, Volume 67, pp. 739-746, 1997.

[11] Chen, Q.H., Au, K.F., Yuen, C.W.M., and Yeung, K.W., "Effects of Yarn and Knitting Parameters on the Spirality of Plain Knitted Fabrics", Textile Research Journal, Volume 73, pp. 421-426, 2003. .

[12] Lord, P.R., "The Structure of Open-End Spun Yarn", Textile Research Journal, Volume 41, pp. 778-784, 1971.
[13] Ahmed, F., "Study of the Impact of Low Twist Rotor Yarn Characteristics on the Quality of Knitted Fabric Produced", Ph.D. Thesis, Mehran University of Engineering \& Technology, Jamshoro, Pakistan, 2013.

[14] Ahmed, F., Rajput, A.W., Sahito, A.R., and Saleemi, S., "Impact of Trifling Quantity of Polyester on Physical Characterization of Low Twist Rotor Spun Yarn", Science International, Volume 26, No. 1, pp. 279-282, 2014.

[15] ISO 16549:2004, "Textiles - Unevenness of Textile Strands - Capacitance Method", International Organization for Standardization, Switzerland, 2004.

[16] ISO 2062:1993, "Textiles - Yarns from Packages Determination of Single end Breaking Force and Elongation at Break", International Organization for Standardization, Switzerland, 1993.

[17] Koc, E., Lawrence, C.A., and Iype, C., "Wrapper Fibres in Open-End Rotor Spun Yarn - Yarn Properties and Wrapper Fibres", Fibres and Textile in Eastern Europe, Volume 13, No. 2, pp. 50-56, 2005.

[18] Candan, C., Nergis, U.B., and Iridag, Y., "Performance of Open-End Spun Yarns in Weft Knitted Fabrics", Textile Research Journal, Volume 70, pp. 177-181, 2000 .

[19] Cooke, W.D., and Kamal, M.S., "Effect of Twist Factor on the Knit Ability of Combed Cotton Yarn", Textile Research Journal, Volume 54, pp. 679-682, 1986.

[20] Saville, B.P., "Physical Testing of Textiles", 1st Edition, Wood Head Publishing Ltd., pp. 154-199, England, 2002. 